\title{
A Survey on the Fatty Acid Composition of Commercial Palm Oil in Thailand
}

\author{
WAYA SENGPRACHA ${ }^{\mathrm{a}}$, MELISSA B. AGUSTIN ${ }^{\mathrm{b}}$ and \\ WEERACHAI PHUTDHAWONG ${ }^{\mathrm{c}^{*}}$
}

${ }^{a}$ Department of Chemistry, Faculty of Science, Silpakorn University, Sanamchan Campus Nakhonpathom- 73000, Thailand

${ }^{b}$ Department of Chemistry, College of Arts and Sciences, Central Luzon State University Science City of Muñoz, Nueva Ecjia-3120, Philippines,

${ }^{c}$ Department of Chemistry, Faculty of Liberal Arts and Science, Kasetsart University, Kampeang Sean Campus, Nakhon Pathom-73140, Thailand

faaswcp@ku.ac.th

Received 14 June 2012 / Accepted 8 July 2012

\begin{abstract}
Seven commercially available palm oils in Thailand were studied to evaluate their fatty acid composition using the GC-MS tandem. Seven to eight different fatty acids distributed in varying proportion were identified in each sample. Saturated fatty acids accounted for 24.82 to $44.65 \%$ of the total fatty acids. Hexadecanoic acid contributed the highest percentage among the saturated fatty acids identified. This was followed by octanoic acid. Dodecanoic, tetradecanoic and eicosanoic acids were also observed in trace amount. The percentage distribution of unsaturated fatty acids with a range of 55.35-75.18\% was determined to be higher than the percentage of saturated fatty acids. 9-Octadecenoic acid largely contributed to the high percentage of unsaturated fatty acids in the palm oil samples. This was followed by 9,12 -octadecadienoic acid. A trace amount of 9,12,15-octadecatrienoic acid was also detected but only in two palm oil samples.
\end{abstract}

Keywords: Fatty acids, Palm oil, Transesterification, GC-MS

\section{Introduction}

The fatty acid composition of vegetable oils has been of great interest in the past since fatty acids play several useful roles to human health. As constituents of lipids in biological membranes, fatty acids affect fluidity, integrity and the activities of membrane-bound enzymes ${ }^{1}$. One of the most significant advances in the understanding of fatty acids is the health benefits derived from the polyunsaturated fatty acids (PUFAs) found in some vegetable or animal-based oil. A diet rich in PUFAs appeared to account for cholesterol lowering which is important in the prevention of cardiovascular diseases ${ }^{2}$. Moreover, the characteristic fatty acid composition of oils has been found useful for evaluating product quality and authenticity ${ }^{3}$.

Palm oil is an edible vegetable oil obtained from the fruit of the oil palm tree. Through different technological processes it has found great applications in food manufacturing and 
in the chemical, cosmetic and pharmaceutical industries. It is used in the manufacture of margarine, cooking oils, soaps and incorporated in various fat blends and a wide variety of food products ${ }^{4-6}$. In Thailand, palm oil accounts for as much as $62 \%$ percent of the vegetable oil market. In fact, a number of palm oil industries are located among the different provinces of Thailand, most of which are in the southern region?

A background on the fatty acid composition of commercial palm oil would greatly benefit consumers who in turn are the end user of this product. Although several studies ${ }^{8-11}$ have reported the fatty acid composition of palm oil, none so far have surveyed the fatty acid composition of commercially available palm oil in Thailand. The palm varieties, growth conditions and plantation management in Thailand are different from other countries ${ }^{7}$, thus fatty acid contents may vary. Moreover, fatty acid composition may be influenced by species or strain, regional, climate, degree of ripeness, harvesting, chemical refining processes and others $^{12}$. In this study, the fatty acid composition of commercially available palm oil in Thailand was determined using the gas column chromatography- mass spectrometry tandem.

\section{Experimental}

A total of seven different brands of palm oil from Tenera variety labeled A-G were obtained from a local market in Chiang Mai, Thailand. Table 1 gives the details for each palm oil sample.

Table 1. Palm oil samples and its respective brand name, company and location of manufacturing company

\begin{tabular}{cclc}
\hline $\begin{array}{c}\text { Sample } \\
\text { code }\end{array}$ & Brand name & \multicolumn{1}{c}{ Company } & Province \\
\hline A & Waew & P.S. Pacific Co. Ltd. & Petchaburi \\
B & Yokh & Lumsoong Co. Ltd & Samutprakarn \\
C & Oline & Oline Co. Ltd. & Bangkok \\
D & Morakhot & Morakhot Industries Co. Ltd. & Samutprakarn \\
E & Thip & Wiwat Industries Co. Ltd. & Nonthaburi \\
F & Reo & Chumporn Palm Oil Industries Co. Ltd. & Chumporn \\
G & Poisian Flower & Morakhot Industries Co. Ltd. & Samutprakarn \\
\hline
\end{tabular}

Preparation of fatty acid methyl esters (FAMEs)

FAMEs were prepared based from the procedure of Pavia et. al. ${ }^{13}$ which was modified by Phutdhawong ${ }^{14}$ as follows. One gram of the oil sample was weighed accurately in a round bottom flask and $20 \mathrm{~mL}$ of methanol and $0.05 \mathrm{~g}$ of sodium was added. The solution was left stirred overnight for the transesterification. The solution was transferred to a separatory funnel to which $10 \mathrm{~mL}$ of water was added and FAMEs were then extracted thrice with $20 \mathrm{~mL}$ dichloromethane per extraction. To the dichloromethane layer, anhydrous sodium sulfate was added to remove water. The extract was concentrated in a rotary evaporator until c.a. $1 \mathrm{~mL}$ solution which was a mixture of FAMEs remained. FAMEs were then kept in a refrigerator until analysis in the GC-MS. GC-MS

\section{Analysis}

Different GC-MS conditions and dilution ratio of the samples were carried out until the optimum conditions that gave the best separation of FAMEs in the sample were achieved. except for sample $\mathrm{G}$ which underwent 20 -fold dilution, all samples were diluted ten-fold before analyzing in the GC-MS (Agilent 6890-HP5975 model). A 1- $\mu \mathrm{L}$ diluted FAME sample 
was injected in split mode (250:1 split ratio) and GC separation was carried out using helium as the carrier gas maintained at c.a. $16 \mathrm{psi}$ and a flow rate of $1.2 \mathrm{~mL} / \mathrm{min}$. HP-5MS $(5 \%$ phenylmethyl siloxane) was used as the capillary column with a nominal diameter of $250 \mu \mathrm{m}$, length of $30 \mathrm{~m}$ and film thickness of $0.25 \mu \mathrm{m}$. The oven temperature was held initially at $150{ }^{\circ} \mathrm{C}$ and later ramped at $4{ }^{\circ} \mathrm{C} / \mathrm{min}$ to $275^{\circ} \mathrm{C}$ and was held isothermally at this point for 30 mins. Chromatograms were obtained in scan mode. The mass spectrometer was operated in electron impact ionization mode. The temperatures of the quadrupole, ionization source and transfer line were $150{ }^{\circ} \mathrm{C}, 230{ }^{\circ} \mathrm{C}$ and $280{ }^{\circ} \mathrm{C}$ respectively.

\section{Identification}

FAMEs were positively identified by matching their mass spectra with literature data derived from two databases: NIST (National Institutes of Standards and Technology) and Wiley.

\section{Results and Discussion}

The transesterification of commercial palm oil produced no emulsion. FAMEs extracted are pale yellow and the percentage yield of fatty acids from the commercial palm oil ranged from $90.70-96.60 \%$.

The results of the GC-MS analysis are summarized in Table 2 and a typical chromatogram of the commercial palm oil is shown in Figure 1. Seven to eight fatty acids distributed in varying amounts were determined in each palm oil samples. A similarity in the pattern of chromatograms was also observed in all the samples. All showed four prominent peaks that correspond to the methyl esters of hexadecanoic acid (peak 3), 9,12-octadecadienoic acid (peak 4), 9-octadecenoic acid (peak 5) and octanoic acid (peak 7). Minor peaks labeled as 1, 2, 6 and 8 corresponds to the methyl esters of dodecanoic $\left(C_{12: 0}\right)$, tetradecanoic $\left(C_{14: 0}\right), 9,12$, 15-octadecatrienoic $\left(\mathrm{C}_{18: 3}\right)$ and eicosanoic $\left(\mathrm{C}_{20: 0}\right)$ acids respectively.

Table 2. Summary of the GC-MS analysis of the commercial palm oils in Thailand.

\begin{tabular}{lcccccc}
\hline \multirow{2}{*}{ Compounds $^{\mathrm{a}}$} & \multicolumn{5}{c}{ Sample code/brand name } \\
& RT $^{\mathrm{b}}$ & RA\% $^{\mathrm{c}}$ & Quality $^{\mathrm{d}}$ & RT $^{\mathrm{b}}$ & RA\% $^{\mathrm{c}}$ & Quality $^{\mathrm{d}}$ \\
\hline Dodecanoic acid methyl ester & 4.58 & 0.20 & 96 & 4.57 & 0.46 & 96 \\
Tetradecanoic acid methyl ester & 7.58 & 0.78 & 99 & 7.57 & 0.68 & 98 \\
Hexadecanoic acid methyl ester & 11.51 & 36.96 & 98 & 11.48 & 28.58 & 98 \\
9,12-Octadecadienoic acid & 14.99 & 10.15 & 99 & 14.99 & 23.91 & 99 \\
methyl ester & & & & & & \\
9-Octadecenoic acid methyl ester & 15.16 & 45.75 & 99 & 15.14 & 39.76 & 99 \\
9,12,15-Octadecatrienoic acid & -- & -- & -- & 15.40 & 0.35 & 97 \\
methyl ester & 15.63 & 4.68 & 99 & 15.62 & 4.62 & 99 \\
Octadecanoic acid methyl ester & 19.74 & 0.18 & 97 & 19.73 & 0.21 & 96 \\
Eicosanoic acid methyl ester & \multicolumn{7}{c}{ C (Oline) } & & D (Morakhot) \\
\hline & 4.56 & 0.19 & 96 & 4.57 & 0.35 & 97 \\
\hline $\begin{array}{l}\text { Dodecanoic acid methyl ester } \\
\text { Tetradecanoic acid methyl ester }\end{array}$ & 7.56 & 0.56 & 99 & 7.57 & 0.94 & 98 \\
Hexadecanoic acid methyl ester & 11.49 & 26.60 & 98 & 11.52 & 36.25 & 99 \\
9,12-Octadecadienoic acid & 15.01 & 23.99 & 99 & 14.99 & 11.07 & 99 \\
methyl ester & & & & & & \\
9-Octadecenoic acid methyl ester & 15.17 & 37.59 & 99 & 15.19 & 45.05 & 99 \\
\hline
\end{tabular}




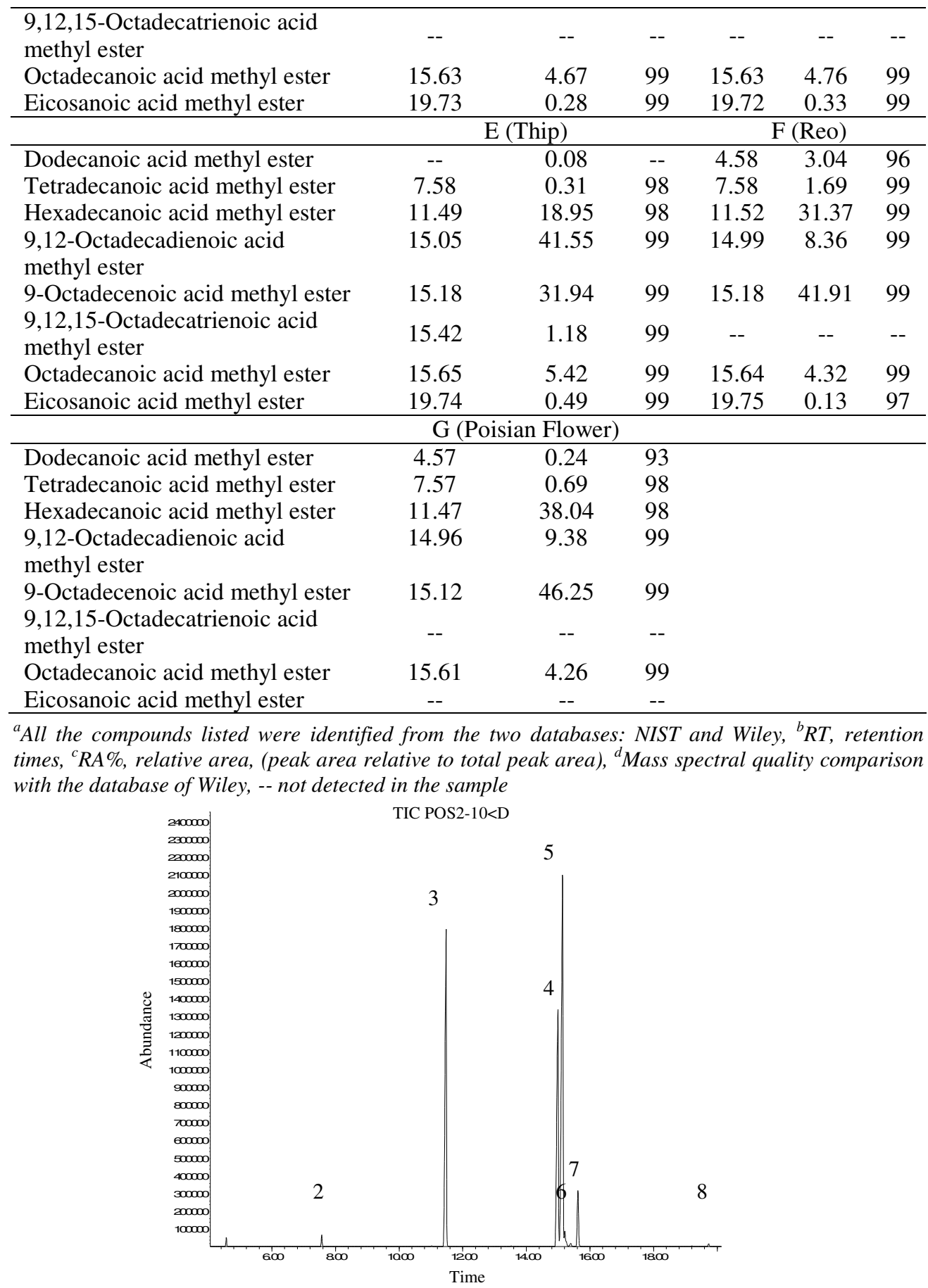

Figure 1. A typical chromatogram of commercial palm oil in Thailand 
The only monounsaturated fatty acid identified in the palm oil samples was 9-octadecenoic acid $\left(\mathrm{C}_{18: 1}\right)$. This acid also contributed the highest percentage in the total fatty acids of all the palm oil samples except with sample $E$. The concentration of $\mathrm{C}_{18: 1}$ ranged from 31.94 to $46.25 \%$, the highest being observed in palm oil sample $F$. The higher concentration of $C_{18: 1}$ over the other fatty acids conforms to the findings of Bora $e t$, al. ${ }^{15}$ with the Brazilian oil palm. However, other monounsaturated fatty acids present in the Brazilian oil palm such as $C_{14: 1}, C_{15: 1}$, $\mathrm{C}_{16: 1}, \mathrm{C}_{20: 1}$ and $\mathrm{C}_{22: 1}$ were not detected. The absence of these monounsaturated fatty acids in the commercially available palm oil may be attributed to several factors as mentioned earlier.

Among the saturated fatty acids determined in the palm oil samples, hexadecanoic acid $\left(\mathrm{C}_{16: 0}\right)$, gave the highest concentration with a range of $18.95-38.04 \%$. The highest concentration of $\mathrm{C}_{16: 0}$ was observed in sample $\mathrm{G}$ and lowest in sample $\mathrm{E}$. The amount of $\mathrm{C}_{18: 0}$ ranged from $4.32-5.42 \%$. Other saturated fatty acids such as $\mathrm{C}_{12: 0}, \mathrm{C}_{14: 0}$, and $\mathrm{C}_{20: 0}$ were also present in small quantities with a concentration of not more than $1 \%$ of the total fatty acids in the palm oil sample. Not included however is sample $F$ whose percentage of $\mathrm{C}_{12: 0}$ and $\mathrm{C}_{14: 0}$ is 3.04 and $1.69 \%$ respectively.

Similar with the palm oil analyses of Bora et. $a l .{ }^{15}$ and Rezanka and Rezanková ${ }^{16}$, only two polyunsaturated fatty acids were detected in the palm oil samples. These were the 9,12-octadecadienoic acid $\left(\mathrm{C}_{18: 2}\right)$ and 9,12,15-octadecatrienoic acid $\left(\mathrm{C}_{18: 3}\right)$. The concentration of $\mathrm{C}_{18: 2}$ ranged from $8.36 \%$ to $41.55 \%$. Although palm oil sample $\mathrm{E}$ gave the lowest amount of $\mathrm{C}_{18: 1}$, it exhibited the highest concentration of $\mathrm{C}_{18: 2}$. A trace amount of $\mathrm{C}_{18: 3}$ was observed only in palm oil samples $\mathrm{B}$ and $\mathrm{E}$ with a concentration of 0.35 and $1.18 \%$ respectively.

Overall, the percentage of saturated fatty acids in the seven palm oil samples have a range of $24.82-44.65 \%$ while unsaturated fatty acids have a range of $55.35-75.18 \%$. The high percentage of unsaturated fatty acids is largely attributed to $\mathrm{C}_{18: 1}$ except for sample $\mathrm{E}$ where $\mathrm{C}_{18: 2}$ was the most predominant fatty acid. Monounsaturated fatty acids have also been reported to be as effective as PUFAs in the reduction of low density lipoprotein cholesterol in humans ${ }^{17}$.

\section{Conclusion}

GC-MS analysis of the 7 commercially available palm oil samples in Thailand revealed seven to eight different fatty acids distributed in varying proportion. The saturated fatty acids identified were $\mathrm{C}_{12: 0}, \mathrm{C}_{14: 0}, \mathrm{C}_{16: 0}$ and $\mathrm{C}_{20: 0}$. Unsaturated fatty acids include the monounsaturated $\mathrm{C}_{18: 1}$ and the polyunsaturated $\mathrm{C}_{18: 2}$ and $\mathrm{C}_{18: 3}$. The percentage distribution of unsaturated fatty acids was observed to be higher than the saturated fatty acids. The monounsaturated $\mathrm{C}_{18: 1}$ largely contributed to the high percentage of unsaturated fatty acids in the palm oil samples.

\section{Acknowledgement}

The authors gratefully acknowledge Thailand Research Foundation (Industry Division) for providing the grant (Grant Code: RDG4850071).

\section{References}

1. Jalali-Heravi M and Vosough M, J Chromatogr A, 2004, 1024(1), 165-176.

2. Binkoski A E, Kris-Etherton P M, Wilson T A, Mountain M L and Nicolosi R J, J Am Dietetic Assoc., 2005, 105(7), 1080-1086.

3. Christopoulou E M, Lazaraki M, Komaitis M and Kaselimis K, Food Chem., 2004, (84)3, 463-474. 
4. Poku, Kwasi, Origin of oil palm, Small-Scale Palm Oil Processing in Africa. FAO Agricultural Services Bulletin 148, Food and Agriculture Organization. ISBN 92-5104859-2, 2002.

5. Wiberg E and Bafor M, Phytochem., 1995, 39(6), 1325-1327.

6. Akpanabiatu M I, Ekpa O D, Mauro A and Rizzo R, Food Chem., 2001, 72(2), 173-177.

7. Agustin $\mathrm{M}$, Sengpracha $\mathrm{W}$ and Phutdhawong $\mathrm{W}$, Int $J$ Environ Res Public Health, 2008, 5(3), 177-180.

8. Ekpa O D, Fubara E P and Morah F N I, J Sci Food Agric., 1994, 64(4), 483-486.

9. Man Che Y B and Setiowaty G, Food Chem., 1999, 66(1), 109-114.

10. Aletor V A, Ikhena G A and Egharevba V, Food Chem., 1990, 36(4), 311-317.

11. Meechaona R, Sengpracha W, Banditpuritat J, Kawaree R and Phutdhawong W, Maejo Int J Sci Technol., 2007, 1(2), 222-228.

12. Lee D, Noh B, Bae S and Kim K, Anal Chim Acta, 1998, 358(2), 163-175.

13. Pavia L D, Lampman G M and Kriz Jr G S, Introduction to Organic Laboratory Techniques, A Contemporary Approach, W.B. Saunders Company, 1976.

14. Phutdhawong W, Kaewkong S and Buddhasukh D, Chiang Mai J Sci., 2005, 32(2) 169-172.

15. Bora Pushkar, Rocha Rosalynd, Narain N, Moreira-Monteiro A and Moreira R, Bioresource Technol., 2003, 87(1), 1-5.

16. Rezanka T and Rezankova H, Anal Chim Acta, 1999, 398(2-3), 253-261.

17. Mensink R P and Katan M B, New Engl J Med., 1989, 321, 436-441. 